\title{
FACTORS INFLUENCING CHILD HEALTH AT THE PERIPHERY OF THE KUMASI METROPOLIS, GHANA
}

\author{
D. Buor \\ Faculty of Social Sciences \\ Kwame Nkrumah University of Science and Technology \\ Kumasi, Ghana
}

\begin{abstract}
The paper examined some of the factors that influence child health at peripheral settlements of the Kumasi Metropolis in Ghana. The simple random technique, supported by purposive procedure, was used to select 240 women whose children were above 2 years but less than 5. Formal interview was the main data collection instrument, whilst linear regression, alongside crosstabulation, was the main analytical tool. Results showed that the principal determinants of child health, in the metropolis were mother's education, household income and exclusive breastfeeding (nutrition). Besides, the use of insecticide bed-nets has been established as having a positive impact on child health. Among the recommendations to improve child health in the locality are the adoption of an integrated approach by appropriate government Ministries and institutions to lift women from the buck of ignorance and poverty through the functional literacy and income generation programmes, whilst steps should be taken to ensure effective formal education of the girl-child. It is recommended that a survey on the impact of childhood immunisation on child health, using a larger sample size, be carried out. A schematic model of the determinants of child health has emerged. This survey has an additional merit of deviating from the normal bivariate and purely descriptive approaches to the use of the multivariate model which evaluates the impact of independent variables.
\end{abstract}

Keywords: child health, urban periphery, women's schooling, exclusive breastfeeding

\section{INTRODUCTION}

Child health in developing countries has been of great concern to nations and international institutions. It is an indicator for measuring the health of populations since the replacement of any population depends, to a large extent, upon the health of the youth. For this reason, child health is among the health issues that dominate the agenda of many countries. Indeed, the control and prevention of infectious diseases affecting children dominate health programmes. At the Millennium Summit in September 2000 the states of the United Nations reaffirmed their commitment to working towards a world in which sustaining development 
and eliminating poverty would have the highest priority. Among the goals was the reduction of child mortality which is an indicator of the health of a nation (The World Bank, 2006). Besides, the Convention drawn on the rights of the child at the 1990 World Summit for Children included specific goals for improving child health. In the production function approach to explaining health outcomes, it is assumed that child health is a function of the household health environment, the parental acquisition of health inputs, and child health endowments (Rosenzweig and Shultz, 1983; Wolpin, 1997).

Admittedly, the need to explore the health conditions of children at the rural-urban interface is urgent. The phenomenal increase in urban populations in Africa is shifting the frontiers to the rural regions, with pressure on the urban land space. At the interface of the two regions emerges a geographical region that is likely to show peculiar demographic and socio-economic characteristics, including the status of child health. The newly created urban frontiers show characteristics, not purely urban, nor rural, but of both. The settlers at the frontiers are mainly rural migrants who are pushed to the urban margins for perceived income and employment opportunities. The choice of such an intersect region will be of great interest. The model that emerges from this study will form the basis for further studies in sub -Saharan Africa and other developing countries having the Ghanaian experience.

The study area which is just near the southeastern fringes of the Kumasi Metropolis and typical of the characteristics of peripheral settlements in the Metropolis, maintains a combination of both urban and rural characteristics. The most common occupations are trading, office and clerical jobs, food and wood processing, farming, building and construction, etc. A survey of such nature would also provide the basis for positioning the health status of the periphery into the structure of health and epidemiological transition. With the complex nature of the problem, a multivariate technique, other than bivariate, is needed to undertake such a survey. These provide the justification for the survey.

Certain research questions emanate from the analysis. First, what are the peculiar characteristics of the urban periphery that have been isolated for study? Such characteristics will provide the foundation for drawing correlations with child health. Second, what are the socio-cultural, economic and demographic factors that show association with child health? Third, is mother's education meaningful in ensuring child health without the corresponding income? Finally, what are the appropriate measures to improve child health at the metropolitan frontier?

The goal of the research is to identify the determinants of child health with the ultimate objective of structuring a model for it. The specific objectives, based on the research questions, are fourfold: Firstly, it is to describe the peculiar socioeconomic, environmental, cultural and demographic characteristics of the study area. Secondly, it is to correlate parents' socio-economic characteristics with child health. Thirdly, it examines how mothers' socio-economic and cultural characteristics have produced behavioural patterns that influence the care of their children. Fourthly, it structures a model of child health at the metropolitan fringes.

The study shall be guided by the following hypotheses:

1. Higher levels of formal education of women result in better health status of their children.

2. Household income exhibits a positive association with child health.

3. Immunisation and exclusive breastfeeding exhibit a positive relationship with child health.

\section{Determinants of Child Health in Low-Income Countries}

The general health patterns in rural and urban areas of developing countries that are in an epidemiological transition reflect child health. Whereas rural populations are more likely to die of diseases 
such as respiratory diseases, malnutrition and diarrhoea, due to underdevelopment, urban populations are more likely to die of heart disease, cancers, diabetes and accidents (Rosenweig and Shultz, 1983). On examining intra-urban differentials it is often possible to detect different stages of the epidemiological transition in different parts of the city in developing countries. This implies that different patterns of morbidity and mortality are due to infectious diseases and chronic diseases respectively. Low-income urban populations exhibit signs of multiple stages of the epidemiological transition suffering the worst of both worlds-underdevelopment and modernisation (Harphan et al., 1988). In the peripheral areas in Bombay for instance, it has been found that residents bear the disease burdens of both poverty and industrial pollution. Wagstaff (2000) in a study of nutrition and health in low-income urban areas of the Third World found that when aggregate rural and urban health indicators are compared, urban areas often appear to have a better health profile. However, when urban data are disaggregated, intra-urban differences emerge to highlight inequity. Basta (1977) showed that while the infant mortality for Manila, Philippines was 76/1000 live births, it was $210 / 1000$ in Tondo, a squatter area within Manila. In a ruralurban interface in developing economies like Ghana, infectious and degenerative diseases that are compatible with poverty are more likely to be prevalent. In Ghana rural areas have lower infant mortality rate than urban (Ghana Statistical Service, 2004a). Whereas the rate is 55 per 1000 live births for the urban areas, it is 70 per 1000 for the rural.

Cornia et al. (1987) analyse the linkages between adjustment policies and child health through changes in food prices and subsidies, family incomes, availability of health services, changes in the relative prices of the goods consumed by the poor, and time use and literacy rates of mothers. Threshold effects in the relationship between economic growth or decline and health status of the population, of which childhood mortality is an important determinant, have been established (Benefo and Shultz, 1996). Even in the industrialised countries, homeless and low-income housed children have been found to experience high rates of acute and chronic illness (Bass et al., 1990; Wood et al., 1990), nutritional problems (Lewis and Meyers, 1989; Fierman et al., 1991; Drake, 1992) and impaired access to health care (Roth and Fox, 1990; Orenstein et al., 1992; Parker et al., 1991).

Following the introduction of the Structural Adjustment Programmes (SAPs) in most African countries, subsidies on health care were removed and this had serious effects on health care, especially maternal and childcare (Ekwempu et al., 1990; Logie and Woodroffe, 1993). Apart from the poverty factor a relationship between fertility and child health has been drawn (Williams et al., 1990). There is a distinct possibility that the correlation between infant mortality and birth rates is a spurious by-product of underlying common determinants, such as women's education, social organisation, health infrastructure, or cultural practices (Hanson et al., 1994).

The education of mothers, among the confounding factors, has been found to have a strong positive impact on the health of children. Culture serves as a barrier to the proper care of children by mothers in developing countries and the attainment of formal education is a factor that enables women to overcome the cultural constraints and prohibitive social norms (Jejeeboboy, 1995). The illiterate use more of traditional medicine (Heggenhougen, 1989) which could be dangerous. In Sub-Saharan Africa, the more the number of years spent in school by women, the higher the survival rate of their children (Hobcraft, 1993).

In Ghana child health and childcare vary significantly by mother's education and place of residence and insignificantly by sex (Ghana Statistical Service, 2004b). Between 1998 and 2003, whereas $11.1 \%$ of under five year old children who had diarrhoea in the two weeks following the survey were children of mothers with secondary educa- 
tion and above, $15.7 \%$ of children having the infection were children of mothers with no education. For place of residence, it was $13.6 \%$ for urban and $16.1 \%$ for rural thus, showing disparities by mother's education and place of residence. There are also differences by vaccination coverage by place of residence and mother's education for all the vaccines.

Another factor affecting child health is injuries which have been estimated to account for $13 \%$ of childhood disease burden and nearly 1 million deaths/year in developing countries, including Africa (Deen et al., 1999; Murray and Lopez, 1999). It has been projected that the relative contributions of injuries and non-communicable diseases to childhood disease burden in developing countries will increase from $28 \%$ in 1990 to $45 \%$ by 2020 (Deen et al., 1999). At the urban periphery like the study area where fertility rate is high hence creating household congestion, child injury rate could be high. A qualitative survey would be required to establish the causes.

\section{DATA AND METHODS \\ The Variables}

The study was basically a cohort, exploratory, and cross-sectional survey involving children of above 2 years and less than 5 years and mothers in their reproductive ages. It is exploratory because such a survey involving rural-urban mix is rare in Ghana. The age limit of children was based on the fact that by two years a child would have gone through all the immunisations, an activity which is a strong determinant of child health. Women selected were in the broad socioeconomic spectra. Independent variables are, household income per month, years of schooling of mother and husband, age of mother, marital status, number of children, average birth interval, immunisation rate, employment status of parent, duration of exclusive breastfeeding, access of health information and use of mosquito bed-nets, while the dependent variable is health status. The mother is the focus since she bears the responsibility of child care.
The dependent variable is health status, as represented by morbidity (frequency of illness spells). Although mortality rates are the most widely used measures of health (Larson, 1991) and are the most important and tractable of the components of health from the point of view of practical application, it could not be used for this study for certain pertinent reasons. First, the number of deaths to parents was not meaningful enough to form the basis for any meaningful analysis. Second, some of the few parents who had lost their children could not tell about the causes of their deaths. Third, for ethical reasons, it was not advisable to go into the details of children's death through interviews. The culture of the people is such that any memory of the death of their children brings melancholic feelings.

Morbidity information was readily available. Parents could easily tell of the disease and health patterns of their children. Mortality, as a measure of health, has been found to have certain deficiencies. It is realised that a decline in the mortality rate may not indicate improved health, since the reality may be that fewer people are dying, but survivors are experiencing increased morbidity (Sullivan, 1981).

\section{Sampling and Data Collection}

Four communities at the urban periphery of $\mathrm{Ku}$ masi metropolis (Ayeduase, Kotei, Deduako and Emena) were selected for the study. The sample was 240 women and their children aged above 2 years but less than 5. As indicated the study involved mothers who have the responsibility of caring for their children, with financial support of their husbands. For communities that had populations above 3000 (Ayeduase, Kotei and Deduako), a sample of 70 was randomly and purposively selected from each, and for Emena which had a population of less than 1500, a sample of 30 was selected. These methods were used to ensure that each child of the defined age had equal chance of being represented to play down on bias. The main research instrument was structured interview, since most of the respondents were either illiterate or semi-literate. 


\section{Measures}

Income of household per month is a combination of cash income and income in kind. Income in kind, like agricultural produce, was converted into cash income. All remittances from diverse sources were factored into the computation. Education is reckoned as the number of years of schooling whilst age is counted as age at the last birthday. Number of children is defined as both biological children as well as non-biological who are taken care of in the household. Birth interval is average birth interval. Marital status is categorised into married and unmarried which were given dummy codes of " 1 " for married and " 0 " for unmarried. Employment is defined as an activity that yields income, whether seasonal or not, and whether income is regular or not. Employed is given code " 1 " and unemployed code ' 0 ". Regarding immunisation, all the ten vaccines and use of vitamin "A" were used. A quantitative value of one was given for each immunisation and one for the use of vitamin "A". A total of 11 was expected for each child who went through all the immunisations and also had a dose of vitamin "A". The vaccines were BCG, DPT1, DPT2, DPT3, polio0, polio1, polio2, polio3, measles, and yellow fever.

Health status, the dependent (outcome) variable, is defined as the percentage of the child's healthy days in the month preceding the survey. This was derived by dividing the number of healthy days of the child by the number of days in the month. For the purpose of cross-tabulation, the values were grouped as follows: $>33 \%=$ Very Poor; $33 \%-50 \%$ =Poor; $51 \%-66 \%=$ Average; $67 \%-83 \%=$ Good; $>83 \%=$ Very Good. Mothers determined the health status of their children. The indicators they used to determine that the children were having illness episodes, apart from the very visible ones such as diarrhoea, nausea, measles, persistent coughs, convulsion etc., were high body temperatures as indication of malaria, break down of appetite with high body temperatures, incessant crying with failure to take a meal, etc.

\section{Data Analysis}

Data were analysed using linear regression (stepwise method). This method was appropriate due to the linearity of the data. The stepwise method has the merit of identifying the key factors that explain the dependent variable. Employment and marital status were entered as dummies. Variables with interaction terms of 0.05 or less were considered significant in the interpretation of the regression results. Bivariate correlations were derived to find possible sources of multicollineaity. Charts were used to depict data.

\section{Characteristics of the Sample}

The socio-economic status of the sample was generally low. The mean years of schooling of the women was 7 (Table 1) which was just at the primary level. What this meant was that most of the women have not completed the Junior High School which is not a terminal that could guarantee one a job in the formal sector. Only $1.6 \%$ of the women sample had had over 15 years of schooling which is within the tertiary level that is likely to secure one a job. The average monthly income per household was Ghø111.48 (\$117.35) with a high standard deviation of Ghф64.82 (\$68.23) implying great differences in income levels. The few receiving very high incomes, business executives and university professors, were not indigenes but the new residents who were senior officers in public and private organisations. The range of income was Gh $\phi 296.00$ (\$311.57). Most residents receive average monthly incomes of less than Ghф60.00 (\$63.15).

Over $83 \%$ of the respondents were married, and, over $20 \%$ were homemakers who depend solely on their husbands for financial support. Average family size was 3 which is just close to the national Total Fertility Rate (TFR) of 3.1 for urban areas and lower than the 5.6 for rural areas (Ghana Statistical Service, 2004 c). The TFR could thus possibly lie between the rural and urban areas of the country. The average birth interval was 39.6 months which is better than the national figure of 38.4 for rural areas, but higher than 43.6 months 
Table 1: Characteristics of the Sample: $\mathbf{N}=\mathbf{2 4 0}$

\begin{tabular}{|c|c|c|c|}
\hline Variable & Mean & $\begin{array}{l}\text { Standard } \\
\text { Deviation }\end{array}$ & Valid Percen \\
\hline Income (d) & Gh $\varnothing 111.48(\$ 117.35)$ & $\phi 64.82(\$ 68.23)$ & $\mathrm{NA}$ \\
\hline Mother's schooling (yrs) & 7.25 & 4.58 & NA \\
\hline Husband's schooling (yrs) & 10.56 & 4.64 & NA \\
\hline Mother's age & 29.23 & 5.87 & $\mathrm{NA}$ \\
\hline \multicolumn{4}{|l|}{ Marital status } \\
\hline Married & & & 13.8 \\
\hline Unmarried & NA & NA & 86.3 \\
\hline Number of children & 2.68 & 1.49 & NA \\
\hline Average Birth Interval (yrs) & 3.31 & 1.17 & NA \\
\hline Immunisations & $8.40 * *$ & 1.92 & NA \\
\hline \multicolumn{4}{|l|}{ Employment } \\
\hline Employed & & & 67.1 \\
\hline Unemployed & NA & NA & 32.9 \\
\hline \multicolumn{4}{|l|}{ Use of Mosquito bed-nets } \\
\hline Yes & & & $71.3 \%$ \\
\hline No & & & $28.8 \%$ \\
\hline Access of health information & 2.25 & 1.33 & NA \\
\hline Duration of exclusive breastf. & 3.19 Months & 2.23 Months & NA \\
\hline *Child health status & 5.49 & 5.10 & NA \\
\hline
\end{tabular}

NB: *Percentage of healthy days in the month;

** Out of a total of 11; Exchange Rate: US\$1=Ghष0.95;

NA=Not applicable

for urban areas (Ghana Statistical Service, 2004d). This confirms the fact that the area maintains a characteristic rural-urban demographic mix.

Since the health problems of mothers have effect on their children, data on mothers' health problems were collected. The main health problems facing women in the area, which reflect the general health trends, were malaria, respiratory tract infections, typhoid, rheumatism, gastroenteritis, hepatitis, and hypertension. As expected, women suffer a lot from gynaecological infections. For the children sample, the top ten diseases are indicated in Table 2. Malaria has been the most serious health problem in the area, as it is in subSaharan Africa. It is a humid area and the poor drainage network and waste management prob- lems create fertile grounds for the breeding of the female anopheles mosquito, the vector.

The health status of the children was nothing to boast of. Only $2.9 \%$ of children sample did not suffer any infection one month following the survey. The health conditions in the area are an indication that it is in epidemiological transition in which preventable diseases predominate. The socio-economic status of the population largely dictates the pattern of health and health care. Studies about child health and the structuring of a model for it should therefore take such a situation into consideration.

\section{RESULTS}

There was no problem of multicollinearity. None of the bivariate correlation coefficients was 0.70 or above. The multiple regression results 
Table 2: Top Ten Childhood Diseases

\begin{tabular}{llcc}
\hline \multicolumn{1}{c}{ Disease } & Frequency & \% \\
\hline 1. & Malaria & 162 & 67.5 \\
2. & Diarrhoeal & 19 & 7.9 \\
3. & Respiratory Tract Infection & 16 & 6.6 \\
4. & Worms & 11 & 4.6 \\
5. & Convulsion & 7 & 2.9 \\
6. & Anaemia & 6 & 2.5 \\
7. & Measles & 4 & 1.6 \\
8. & Polio & 3 & 1.3 \\
9. & Typhoid & 3 & 1.3 \\
10. & Others & 9 & 3.8 \\
& TOTAL & 240 & 100.0 \\
\hline
\end{tabular}

NB: The diseases are the most prevalent reported for each child.

Table 3: Multiple regression (Stepwise) Factors

\begin{tabular}{lcccc}
\hline \multicolumn{1}{c}{ Variables/Model } & $\begin{array}{c}\text { Beta } \\
\text { Coefficients }\end{array}$ & $\begin{array}{c}\text { Standard } \\
\text { Error }\end{array}$ & $\begin{array}{c}\text { Significant/ } \\
\text { Probability Level }\end{array}$ & $\begin{array}{c}\text { Adjusted } \\
\mathbf{R}^{\mathbf{2}}\end{array}$ \\
\hline Mothers' Education & 0.803 & 0.057 & 0.000 & 0.644 \\
Mothers' Education & 0.638 & 0.074 & 0.000 & \\
Household Income & 0.244 & 0.000 & 0.000 & 0.674 \\
Mothers' Education & 0.581 & 0.078 & 0.000 & \\
Household Income & 0.232 & 0.000 & 0.000 & 0.684 \\
Exclusive Breastfeeding & 0.126 & 0.135 & 0.010 & \\
\hline
\end{tabular}

(stepwise method) are indicated in Table 3. Four independent variables namely, mothers' education (years of schooling), household income, and exclusive breastfeeding emerged as key determinants of child health. The high beta value for mothers' education makes it the most important determinant. The use of mosquito bed-nets has also emerged as a strong determinant of child health as indicated by Fig. 1. Cross-tabulation also shows that the difference in health status by the use of the bed-net is very significant (Table 4). The probability value is 0.000 . The use of the interactive map (scatterplot) (Fig. 2) clearly de- picts the strength of the impact of mothers' education on child health.

\section{DISCUSSION}

The periphery of the Kumasi metropolis exhibits a mixture of rural and urban characteristics which reflect a low stage of epidemiological transition. Preventable diseases such as malaria, typhoid, diarrhoea, intestinal worms and anaemia have their toll on children whilst infections like measles and polio against which children are vaccinated have reduced considerably. Though the health status of children in the area was better than in a 
first year, 582 T. zillii made up of 378 males and 204 females were caught. This was followed by 717 specimens (359 males and 358 females) in the second year while 187 specimens (130 males and 57 females) were caught in the early months of the third year (Figure 2). A large area of shoreline that was exposed in the dry seasons was submerged during the rainy seasons. The smallest fish specimen caught had a standard length of $8.5 \mathrm{~cm}$ and a total length of $11.7 \mathrm{~cm}$ with a weight of $39 \mathrm{gm}$. The biggest fish caught had standard length, total length and a weight of $22.0 \mathrm{~cm}$, $29.0 \mathrm{~cm}$ and $397 \mathrm{gm}$, respectively showing a wide range of fish sizes.

Forty four gillnet samplings were made in each of the reservoir segment. Out of 821 fish specimens, $31.08 \%$ were caught in the dam area while $48.65 \%$ and $20.27 \%$ in the middle and upper segments of the reservoir, respectively. T. zillii was not spatially distributed when tested statistically $\left(c_{\text {cal. }}^{2} 27.39<\mathrm{c}_{\text {tab. }}^{2}\right.$ 67.51; df. 820).

Fish specimens caught near the water surface by gillnetting were $9.5 \%$ while the majority of fish specimens were caught in the lower part of the gillnet. T. zillii was not concentrated near the surface of water as tested statistically $\left(\mathrm{c}^{2}\right.$ cal. $557.9>$

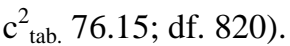

The reservoir inshore area with a mean of 8.71 metres long was the littoral zone where light penetrates to the substratum. The offshore area was beyond the photic zone. Thirty-three gillnet samplings were made on each side of the reservoir representing inshore distribution while sixtysix gillnet samplings were made along the reservoir mid-water indicating offshore distribution. Out of 821 fish specimens, $68.7 \%$ were caught in the inshore area and $31.3 \%$ at the offshore area of the reservoir. $T$. zillii was mostly found within the inshore area of the reservoir $\left(c^{2}\right.$ cal. $217.6>c^{2}$ tab. 76.15; df. 820).

The percentage composition of 821 fish specimens caught by different stretched mesh sizes of $2.5 \mathrm{~cm}, \quad 5.1 \mathrm{~cm}, 7.6 \mathrm{~cm}, 10.2 \mathrm{~cm}$ and $12.7 \mathrm{~cm}$ amounted to $2.92 \%, 23.5 \%, 34.23 \%, 39.34 \%$ and
$0 \%$ respectively. The mean total length of the fish specimens caught by $2.5 \mathrm{~cm}, 5.1 \mathrm{~cm} .7 .6 \mathrm{~cm}$ and $10.2 \mathrm{~cm}$ stretched mesh sizes were $17.8 \mathrm{~cm}, 19.7 \mathrm{~cm}$ $25.4 \mathrm{~cm}$ and $31.1 \mathrm{~cm}$, respectively.

The stomach contents of 665 specimens of $T$. zillii caught by castnetting were examined. The species fed mostly on algae, higher plants, diatoms and zooplankton (Table 2). The undigested higher plant fragments were identified as Amaranthus hibridus Linn., Commelina diffusa Burm, C. erecta Linn and Acrocera zizanioides (Kunth) found at the shoreline of the reservoir. Food items such as Phacus sp, higher plant fragments, Ankistrodesmus sp, Navicula spp and Melosira sp were mostly ingested throughout the study period. Small fish specimens with size ranges between $10.0 \mathrm{~cm}$ and $17.9 \mathrm{~cm}$ total length and less than three years of age fed on twelve food

items while big fish sizes above $18.0 \mathrm{~cm}$ and above three years of age fed on all identified food items (Table 3). Food items not available in the dry season included Spirogyra sp. And Pediastrum sp. while Ostracod sp., Sceneddesmus sp. and Peridinium sp. were not in the fish diet during the rainy seasons.

Observations on the diurnal feeding rhythm in the field and analysis in the laboratory show that fish specimens with full stomachs between the hours of $6.00 \mathrm{am}$ and $9.00 \mathrm{am}$ were $7.98 \%$ of the total catch. During the same period $28.90 \%$ had threequarter stomach fullness and $27.59 \%$ were with half stomach fullness. However, the number of fish with full stomach increased to $53.23 \%$ between 12.00 mid-day and $3.00 \mathrm{pm}$ (Table 4). Fish specimens with full stomachs decreased to $6.08 \%$ between $3.00 \mathrm{pm}$ and $6.00 \mathrm{pm}$ (Figure 3 ). A total of $82.85 \%$ of all fish specimens caught in the reservoir fed between $6.00 \mathrm{am}$ and $3.00 \mathrm{pm}$. In Opa reservoir, $T$. zillii fed during the day and the peak feeding period was between 12.00 mid-day and $3.00 \mathrm{pm}$.

\section{DISCUSSION}

About twenty percent of fish specimens in this study were caught in the upper segment of the 


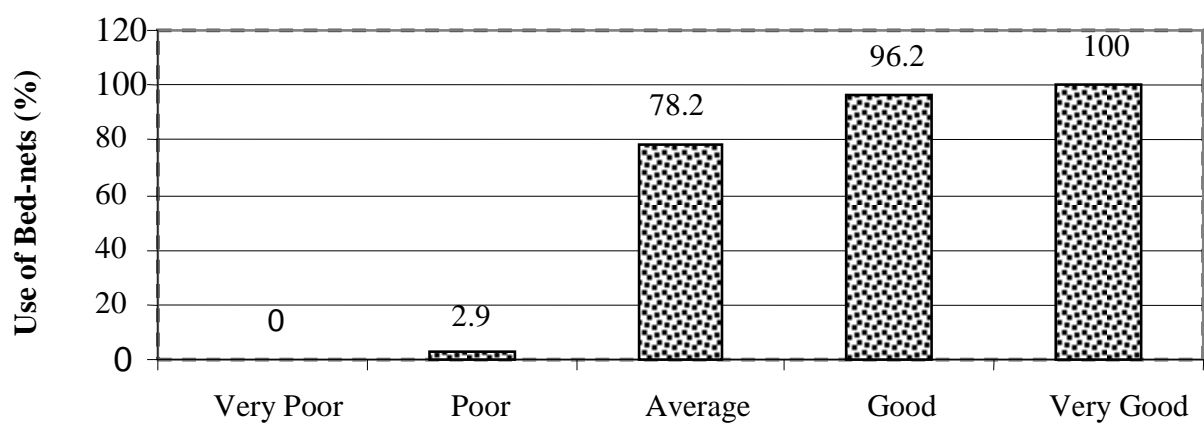

Child Health

Fig. 1: Use of Mosquito Bed-nets and Child Health

Table 4: Use of Mosquito Bed-Nets and Child Health

\begin{tabular}{lccc}
\hline \multirow{2}{*}{ Health Status } & \multicolumn{2}{c}{ Use of bed-nets } & \multirow{2}{*}{ Total } \\
& Yes & No & \\
\hline Very Poor & 0 & 13 & 13 \\
Poor & 1 & 34 & 35 \\
Average & 68 & 19 & 87 \\
Good & 76 & 3 & 79 \\
Very Good & 26 & 0 & 26 \\
Total & 171 & 69 & 240 \\
\hline
\end{tabular}

Pearson Chi-Square $=148.671 ;$ Sig. $=0.000$

typical rural community in Ghana, it was not very satisfactory compared with a typical urban centre. This survey has established that the main factors that influence the health status of children of under-five years are mothers' education, household income, and exclusive breastfeeding. The hypothesis that immunisation has a positive effect on child health has not been vindicated. Immunisation has not emerged as a significant factor, going by the regression results even though preliminary survey established the fact that the children of mothers who took their children through all the immunisations reported insignificant illness episodes that immunisations address. The possible reason responsible for this is that child immunisation rate is generally high. The average immunisations exceed eight out of the eleven and the standard deviation a little over one. Vaccination in the first year of birth is the only significant factor in child mortality (Gloria et al., 2003).

Mothers' schooling is strongly associated with child health. In Ghana, the demographic and health surveys have proved that mothers with high education use medical facilities for both themselves and their children more than those with low or no education at all (Ghana Statistical Service, 2004e). The hypotheses that higher levels of mothers' education and household income which are key socioeconomic factors result in better child health has been vindicated by this survey. Globally and historically, socioeconomic status is among the most important health determinants throughout the life course (Spencer, 2000). Pov- 


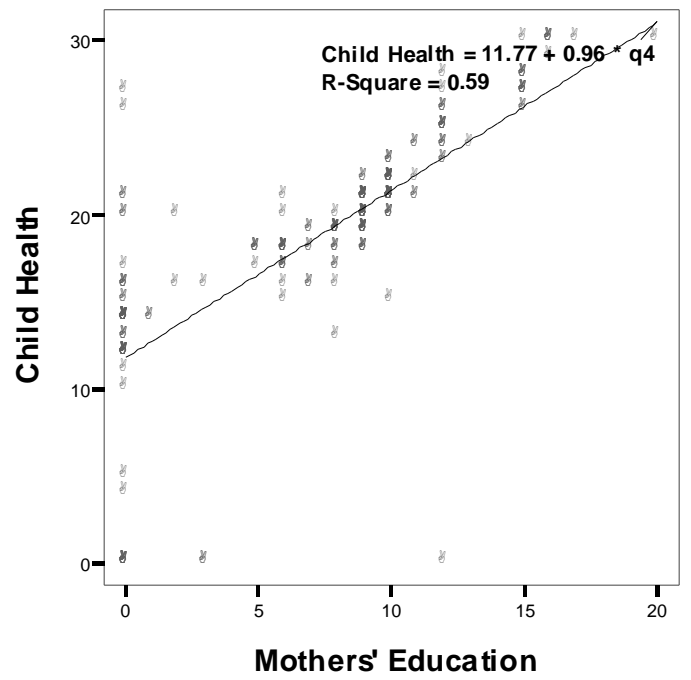

Fig. 2: Mothers' Education and Child Health

erty and low socioeconomic status are associated with higher risk of death in infancy and childhood, chronic childhood illness, and many acute illnesses. It has also been found that the longer the child is exposed to adverse social conditions and he worse the social conditions, the greater the effect (Smith, 1999; Wagstaff et al., 2004; Armar -Klemesu, 2004; Shehzad, 2006).

Nutrition has also emerged as an important determinant. Child survival, which is one of the eight Millennium Development Goals (MDGs), can be achieved only if steps are taken to improve child nutrition. According to the WHO, the proportion of children under five in the developing world who are malnourished to the point of stunting fell from $39 \%$ in 1990 to $30 \%$ in 2000 . This figure was projected to fall to $26 \%$ in 2005 (The World Bank, 2007). Implementing interventions that improve child nutrition will reduce child deaths significantly. For instance, interventions that would improve child nutrition and provide clean water and sanitation and clean household fuels to all children younger than 5 years would result in an estimated annual reduction in child deaths of 1.47 million $(31 \%)$ in sub-Saharan Africa
(Gakidou et al., 2007). Exclusive breastfeeding which was used as an indicator of nutrition improves both the physical and mental development of the child (Daniels and Adair, 2005).

Policy implications in addressing the problem of child health include intensification of the education of the girl-child and the functional literacy programme. A Ministerial integration approach should be adopted. The Ministries of Education, Science and Sports, Health, Women and Children's Affairs and Food and Agriculture should be involved in the exercise. Whilst the Ministry of Education takes care of the formal education and functional literacy that of Women and Children's Affairs should organise sensitisation workshops to work out programmes to financially empower women through gainful employment. Agricultural extension officers that regularly interact with farmers could also be a channel of the educational programme. Government's Free Compulsory Universal Basic Education (FCUBE) programme must be strengthened through provision of personnel and logistics to achieve its lofty goals. This should be supported by health education provided by the medical staff during consultations. 
Secondly, the income opportunities of women must improve by instituting vocational training programmes to enhance their employable skills. They must have easier access to bank credits to carry out micro businesses. Improvement in household incomes would improve access of health services for women and their children and improve nutrition. Women's education and income must combine to ensure the proper care of their children. Exclusive breastfeeding, apart from the appreciation of the need to do so by mothers, would depend to a significant extent on maternal nutrition which is dependent on resources available to them. Parents must be encouraged to enrol on the national health insurance scheme in order to reduce the financial barriers to the use of quality health services. In the study area, access roads to the centre of the metropolis must be improved to facilitate access to health facilities.
Thirdly, Integrated Management of Child Illnesses (IMCI) strategy developed since 1995 by the World Health Organisation (WHO) in cooperation with United Nations Children's Fund (UNICEF) must be adopted. The IMCI aims at adopting an integrated approach to child health and development of national health policies, focusing on the improvement of health-care staff's case management skills, the improvement of the overall system and of family and community health practices (The World Bank 2007). Finally, parents must be encouraged to provide mosquito bed-nets for their children to protect them from the sting of the vector and the malaria scourge. The cost of bed-nets must be heavily subsidised to be affordable.

A model of the determinants of child health at the urban periphery emerges (Fig. 3). The model is built from the regression and cross-tabulation results. The model shows that the fundamental fac-

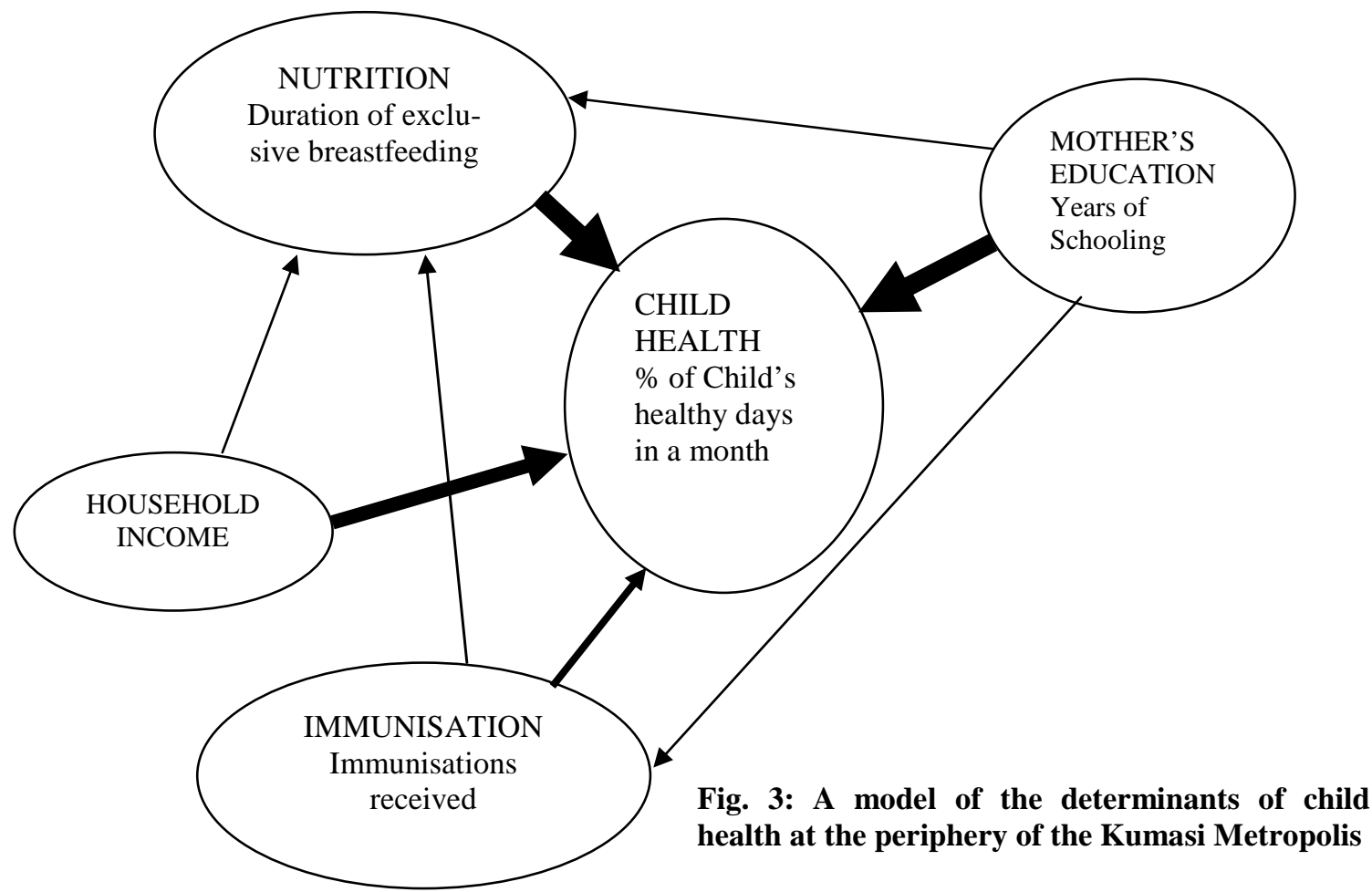


tors that influence child health are the mother's education, household income, nutrition and immunisation.

\section{CONCLUSIONS}

The peripheral settlements of the Kumasi Metropolis are in a state of epidemiological transition, as reflected in the health status of children. Some preventable diseases predominate. The state of development gives credence to such a status. The educational status of women who are responsible for the health care of their children, duration of exclusive breastfeeding (nutrition) and household incomes are low. It follows as a logical consequence that child health is primarily influenced by mothers' education which also affects income and also influences breastfeeding. The three variables are thus interrelated. Besides, the use of mosquito bed-nets to protect children from malaria, the most common and fatal disease, would be influenced by mothers' education and income. Three policies are urgent: strengthening of institutions responsible for the education of the girlchild and the functional literacy programme for illiterate women; improving income opportunities of women through vocational training and easy access to bank credit to facilitate the establishment of small-scale businesses; and effective campaign on effective breastfeeding. Improvement in income levels has related advantages of enhancing access of health facilities and nutrition. Further research directions are proposed: the impacts of immunisation and high fertility on child health need to be examined, using larger sample sizes.

\section{REFERENCES}

Armar-Klemesu, M. (2000). Poor maternal schooling is he main constraint to good child care practices Accra. Journal of Nutrition 130(6): 1597-1607.

Bass, J.L., Brennan, P., Metha, K.A., Kodzis, S. (1990). Paediatric problems in a suburban shelter for homeless families. Paediatrics 85 : 33-38.
Basta, S.S. (1977). Nutrition and health in lowincome urban areas of the Third World. Ecology of Food and Nutrition 6: 13-24.

Benefo, K. and Schultz, T.P., (1996). Fertility and Child Mortality in Cote d'Ivoire and Ghana. The World Bank Economic Review, 10 (1): 123-158.

Cornia, G.A., Jolly, R., Stewart, F. (1987). Adjustment with a Human Face, Vol. 1., Oxford: Claredon Press, 344p.

Daniels, M.C., Adair, L.S. (2005). Breastfeeding influences cognitive development in Filipino children. Journal of Nutrition 135(11): 25892595.

Deen, J.L., Vos, T., Huttley, S.R.A., Tulloch, J. (1999). Injuries ad non-communicable diseases: emerging health problems of children in developing countries. Bulletin of World Health Organisation 77: 518-524.

Drake, M.A. (1992). The nutritional status of dietary adequacy of single homeless women and their children in shelters. Public Health Rep 1107: 312-319.

Ekwempu, C.C., Maine, D., Olorukooba, M.B., Esien, E.S., Kisseka, M.N. (1990). Structural adjustment and health in Africa. Lancet 336: 56-57.

Fierman, A.H., Dreyer, B.P., Quinn, L., Shulman, S., Courtland, C.D., Guzzo, R. (1991). Growth delay in homeless children. Paediatrics 88: 918-925.

Gakidou, E., Oza, S., Vidal Fuertes, C., Li, A.Y., Lee, D.K. (2007). Improving child survival through environmental and nutritional interventions: the importance of targeting interventions toward the poor. Journal of American Medical Association, 298(16): 18761887.

Ghana Statistical Service (GSS), Nouguchi Memorial Institute for Medical Research, LegonGhana and ORC Macro, Calverton, Maryland, USA (2004a). Ghana Demographic and Health Survey 2003. p.129. 
Ghana Statistical Service (GSS), Nouguchi Memorial Institute for Medical Research, Legon -Ghana and ORC Macro, Calverton, Maryland, USA (2004b). Ghana Demographic and Health Survey 2003. pp.154, 160.

Ghana Statistical Service (GSS), Nouguchi Memorial Institute for Medical Research, Legon -Ghana and ORC Macro, Calverton, Maryland, USA (2004c). Ghana Demographic and Health Survey 2003. p.56.

Ghana Statistical Service (GSS), Nouguchi Memorial Institute for Medical Research, Legon -Ghana and ORC Macro, Calverton, Maryland, USA (2004d). Ghana Demographic and Health Survey 2003. p.60.

Ghana Statistical Service (GSS), Nouguchi Memorial Institute for Medical Research, Legon -Ghana and ORC Macro, Calverton, Maryland, USA (2004e). Ghana Demographic and Health Survey 2003. p.145.

Gloria, M. Gebrenegus, G., Eva, B., Bo, B., (2003). Trends in infant and child mortality in Mozambique during and after a period of conflict. Public Health 117(4): 221-227.

Hanson, L.A., Bergstrom, S., Rosero-Bixby, L. (1994). Infant Mortality and Birth Rates. In, Lankinen, K.S., Makela, P.H., Peltomaa, M. Health and disease in developing countries. London: The Macmillan Press Limited, 3748.

Harphan, T., Lusty, T., Vaughan, P. (1998). In the shadow of the city: community health and urban poor. Oxford: Oxford University Press, pp.83-89.

Heggenhougen, H.K. (1989). Perceptions of health-care options and therapy-seeking behaviour. (1989). In: John Cleland and Allan G. Hill (eds). The Health Transition: Methods and Measures. Cambridge University Press: (Book 3). pp. 133-146.

Hobcraft, J.N. (1993). Women's education, child welfare and survival: a review of the evidence. Health Transition Review. 3: 150-175.
Jejeebhoy, S.J. (1995). Women's education, autonomy, and reproductive behaviour: experience from developing countries. New York: Oxford University Press, 306pp.

Larson, S.J. (1991). The Measurement of Health, Concepts and Indicators,: New York: Greenhood Press. p.19.

Lewis, M.R., Meyers, A.F. (1989). The growth and development status of homeless children entering shelters in Boston. Public Health Rep 104: 247-250.

Logie, D.E., Woodroffe, J. (1993). Structural adjustment: the wrong prescription for Africa? BMJ 307:41-44.

Murray, C.J.L., Lopez, A.D. (1994). Global and regional cause-of-death pattern in 1999. Bulletin of World Health Organisation 72: 447480.

Mwabu, G. (1996). Health effects of Marketbased Reforms in Developing Countries, Working Paper, No. 20, UNU/WIDER, Helsinki.

Orenstein, J., Boenning, D., Engh, E., Zimmerman, S. (1992). Emergency care of children in shelters. Pediatric Emergency Care, 8(6): 313 -317 .

Parker, R.M., Rescorla, L.A., Finkelstein, J.A., Barnes, N., Homles, J.H., Stolley, P.D. (1991). A survey of the health of homeless children in Philadelphia shelters. Am J Dis Child 145: 520-526.

Pritchett, L. and Summers, L.H. (1996). Wealthier is Healthier. The Journal of Human Resources (4):841-868.

Rosenzweig, M.R. and Schultz, P.T. (1983). Estimating a household production function: Heterogeneity, the demand for health inputs, and their effects on birth weight.' Journal of Political Economy 91(5): 723-746.

Roth, L., and Fox, E.R., (1990). Children of homeless families: health status and access to health care. Journal of Community Health, 15: 275-284. 
Shehzad, S. (2006). The determinants of child health in Pakistan: an economic analysis. Social Indicators Research, 78(3): 531-556.

Smith, J.R., Brooks-Gunn, J., Klebanov, P. (1997). The consequences of living in poverty for young children's cognitive and verbal ability and early childhood achievement. In: Duncan G.J., Brooks-Gunn J., eds. The consequences of growing up poor. New York, NY: Russell Sage Foundation, p.132189.

Spencer, N.J. (2000). Poverty and child health $2^{\text {nd }}$ Ed., Abingdon, United Kingdom: Radcliffe Medical 352pp.

Sullivan, D.F (1981). Conceptual Problems in Developing an Index of Health National Canter for Health Statistics, $D H E W$, Series 2, No. 17.

The World Bank (2006). World Development Indicators, Washington DC. p.3.
The World Bank (2007). Child Health and Nutrition. The World Bank Group, Washington DC. pp.1-4.

United Nations Children Fund (UNICEF). (1996). The state of the world's children. New York: Oxford University Press.

Williams, T., Moon, A., Williams M. (1990). Food, environment and health. Guide for primary school teachers. Geneva: WHO. 129p.

Wolpin, K.I. (1997). 'Determinants and consequences of the mortality and health of infants and children.' In: Handbook of Population and Family Economics, (ed). Rosenzweig and Stark O., Vol. 1A: Amsterdam: Elsevier Science B.V., pp.483-557.

Wood, D.L., Valdez, B., Hayashi , T., Shen, A. (1990). Health of homeless children and housed, poor children. Paediatrics. 86: 858866. 